\title{
The dietary treatment of inborn errors of metabolism
}

\section{By L. I. Woolf, Kinsmen Laboratory of Neurological Research, Department of Psychiatry, University of British Columbia, Vancouver V6T I $W_{5}$, British Columbia, Canada}

In the course of evolution, man has acquired digestive enzymes that split complex food components to simpler, absorbable molecules, biosynthetic enzymes that reform complex body components and degradative enzymes that catabolize these components. Each enzyme is a protein and its biosynthesis is under genetic control. Mutation of the gene coded for the enzyme, or for one polypeptide where an enzyme molecule consists of more than one polypeptide chain, can lead to inactivity of that enzyme which, in turn, often leads to serious disease. These diseases are the inborn errors of metabolism. The specific carrier mechanisms that transport molecules across membranes (e.g. in the jejunum, renal tubules, etc.) are also based on specific proteins, the biosynthesis of each being under genetic control; mutation of these genes leads to a second group of inborn errors of metabolism affecting, e.g., absorption from the gut.

Primary alactasia, the inherited absence of intestinal lactase ( $\beta$-galactosidase; $E C$ 3.2.1.23), leads to inability to hydrolyse lactose, which therefore enters the colon and is fermented by the gut flora (Holzel, 1962; Prader \& Auricchio, 1965; Dahlqvist \& Asp, 1975). The infant fails to gain weight (lactose is an important part of the newborn infant's total energy intake) and has diarrhoea with frothy, acid stools. The situation is life-threatening unless the lactose of the milk is replaced by some other carbohydrate, e.g. glucose, in an artificial mixture which otherwise resembles milk.

In galactosaemia the enzyme galactose-1-phosphate uridylyltransferase ( $E C$ 2.7.7.10) is absent or inactive. This causes accumulation of the enzyme's normal substrate, galactose-1-phosphate and, by 'back-up', of galactose. Galactose-Iphosphate is toxic: untreated patients usually die, and the survivors suffer damage to the liver (cirrhosis), the brain (mental retardation), the kidneys (renal tubular dysfunction) and the eyes (cataracts). Treatment is with a diet free from galactose (Woolf, 1962; Hsia, 1969; Segal, 1972; Kalckar, Kinoshita \& Donnell, 1973). This is usually effective if started in earliest infancy but some infants show an incomplete response, the result, it is believed, of irreversible damage by galactoseI-phosphate that accumulated in utero.

Perhaps the best-known of the treatable inborn errors of metabolism is phenylketonuria (PKU). The amino acid phenylalanine is normally oxidized through a series of steps, each catalysed by a specific enzyme, to urea, carbon dioxide and water. The first step is oxidation of phenylalanine to tyrosine by molecular oxygen in the presence of phenylalanine 4 -hydroxylase ( $E C$ I.14.3.1), an 
enzyme found only in liver cells, and a cofactor, tetrahydrobiopterin. In PKU, because of mutation of the relevant gene, phenylalanine 4-hydroxylase is absent or inactive and, in consequence, phenylalanine accumulates in the blood and tissues. The phenylalanine in the body fluids and tissues competes with other amino acids for entry into the neurons, reducing the rates of synthesis of enzymes, other proteins and neurohormones (synaptic transmitters). The phenylalanine may also inhibit key enzymes in the neurons.

The more important clinical features of PKU are mental retardation, usually severe or profound (median intelligence quotient $(\mathrm{IQ})<20$ ), abnormalities of the electroencephalogram (EEG) (in 90-95\%), behavioural disorders and, in $25 \%$, epilepsy (Bickel, Hudson \& Woolf, I971; Knox, 1972). The brain is small with a marked deficiency of myelin (Crome, Tymms \& Woolf, 1962). Of all the organs in the body, only the brain seems sensitive to the toxic action of phenylalanine (except in the foetus in maternal PKU).

In 1949 it was suggested that a diet low in phenylalanine might prevent or ameliorate the mental retardation and other consequences of PKU, and ways to prepare such a diet were put forward (Woolf \& Vulliamy, 1951; Bickel, Gerrard \& Hickmans, 1953; Armstrong \& Tyler, 1955; Woolf, Griffiths \& Moncrieff, 1955). The procedure used for many years was to replace dietary protein with a protein hydrolysate which had been passed through charcoal to remove phenylalanine. Tyrosine, tryptophan, methionine and just enough natural protein to supply the phenylalanine needed for growth were added. Since the diet was virtually entirely synthetic, a complete vitamin and mineral supplement, polyunsaturated fats and carbohydrates were added in appropriate amounts. Several companies have now produced dry powders containing all or most of the ingredients except the natural protein.

In the last 25 years several hundred, perhaps 1000, children with PKU have been treated with a low-phenylalanine diet and the effects can be assessed. If started late, after the occurrence of some brain damage as shown by, e.g. mental retardation, there is usually marked improvement in behaviour, in the EEG, in the frequency of epileptic seizures and, depending on the duration of exposure to phenylalanine and the extent of retardation, often a slow rise in the IQ (Woolf, Griffiths, Moncrieff, Coates \& Dillistone, 1958; Coates, 196r; Bruhl, 1966; Baumeister, 1967; Bickel, 1967; Fischler, 1971). However the most satisfactory results have come where treatment was started in the first few weeks of life. The I 45 infants in the Collaborative PKU Study in the USA comprise the largest and best-studied group; great precautions were taken to exclude phenylalaninaemia variants and other factors that might distort the results (Koch, Dobson, Blaskovics, Williamson, Ernest, Friedman \& Parker, 1973). The mean IQ is 100 (SD 12), i.e. completely normal both in mean and variance. However, the unaffected siblings of the PKU patients have a mean IQ of 108 , which is significantly higher. None of the 145 shows any signs of neurological disease and all are growing normally. Hence the low-phenylalanine diet is achieving the results hoped for and the intoxication hypothesis on which the diet is based appears to be sound. 
The content of phenylalanine, an essential amino acid, in the diet given to these infants would be grossly inadequate for a normal infant who irreversibly oxidizes phenylalanine by means of phenylalanine 4-hydroxylase. PKU can be regarded as an amino acid imbalance: the phenylketonuric patient has enzymes adapted to deal with 'protein' of very much lower phenylalanine content, relative to the other amino acids, than that of ordinary dietary proteins.

The success of the dietary treatment of phenylketonuria has led to the use of similar restrictive diets in treating other inborn errors of amino acid metabolism. Dietary restriction, generally of specific amino acids, has been successful in the treatment of leucinosis (maple-syrup urine disease), valinaemia, isovaleric acidaemia, $\beta$-methyl-crotonylglycinuria, propionic acidaemia (one type of ketotic hyperglycinaemia), an isoleucine-related type of ketotic hyperglycinaemia, D- and L-methylmalonic acidaemias, non-ketotic hyperglycinaemia, hyperprolinaemia, citrullinaemia, argininosuccinic aciduria, hyperammonaemia types I and II, hyperargininaemia, homocystinuria, histidinaemia, cystinosis, hyperlysinaemia, saccharopinuria and ornithinaemia.

Leucinosis (maple-syrup urine disease) was the first of these disorders, after PKU, to have dietary treatment proposed and tried (Mackenzie \& Woolf, 1959; Dent \& Westall, 196r; Snyderman, 197r; Auerbach \& Di George, 1973). The disease involves three essential amino acids, leucine, isoleucine and valine. The three transaminases are normal, but the three a-keto acids formed cannot be decarboxylated and therefore accumulate. The three $\alpha$-keto acids and their parent amino acids are toxic, causing fairly rapid cerebral degeneration and death, sometimes within 2 weeks of birth. A diet low in leucine, isoleucine and valine is not only life-saving but, in most instances, permits normal mental and physical growth and development.

A patient with a milder variant of leucinosis, with some residual enzymic activity and much less severe clinical features, was found to respond well to massive doses of thiamin, up to $20 \mathrm{mg} / \mathrm{d}$, which partially corrected the biochemical error (Scriver, Mackenzie, Clow \& Delvin, 1971). Similar use of pharmacological doses of vitamins as the treatment of inborn errors of metabolism are the use of pyridoxine in infantile spasms caused by deficiency of glutamate decarboxylase (EC 4.1.1.15), in xanthurenic aciduria and in about $50 \%$ of cases of homocystinuria, and biotin in tiglylglycinuria and in one form of propionic acidaemia.

There are other inborn errors of metabolism or transport of the vitamins themselves, e.g. an enzyme which normally converts a vitamin to a cofactor for another enzyme may be defective, leading to clinical disease which may resemble a vitamin deficiency or may mimic an inborn error of, e.g., amino acid metabolism. The metabolism of vitamin $B_{12}$ and of folic acid provide examples. There are four known inborn defects of vitamin $B_{12}$ transport (three leading to megaloblastic anaemia) and two of hydroxocobalamin intermediary metabolism (Rosenberg \& Mahoney, 1973). One of the latter two leads to decreased synthesis of $5^{\prime}$ deoxyadenosylcobalamin and manifests itself as a severe, often fatal, form of methylmalonic aciduria ( $5^{\prime}$-deoxyadenosylcobalamin is the cofactor for L- 
methylmalonyl-CoA mutase; $E C$ 5.4.99.2); it responds to 500-100 $\mu \mathrm{g}$ vitamin $B_{12}$ daily. The other inborn error leads to decreased conversion of vitamin $B_{12}$ to both $5^{\prime}$-deoxyadenosylcobalamin and methylcobalamin, the cofactor for the enzyme methyltetrahydrofolate methyltransferase which converts homocysteine to methionine; the clinical and biochemical features are those of methylmalonic acidaemia combined with an unusual type of homocystinuria.

There are five known inborn errors of folic acid metabolism (Luhby, Eagle, Roth \& Cooperman, 196r; Walters, r967; Arakawa, 1970; Mudd, Uhlendorf, Freeman, Finkelstein \& Shih, 1972). Two of these respond to large doses of folic acid (10-20 $\mathrm{mg}$ orally/d) and one responds to parenteral 5 -formyltetrahydrofolic acid (100 $\mu \mathrm{g} / \mathrm{d}$ ) but not to folic acid. Mental retardation, neurological disease and 'reversible schizophrenia' are prominent features of these conditions, one of which leads to yet another form of homocystinuria (for lack of methyltetrahydrofolic acid); only three involve megaloblastic anaemia.

The dramatic results achieved by dietary treatment of several inborn errors of metabolism, in which the physical and intellectual status of the patients were greatly improved, tended to concentrate attention on these aspects. However, a special diet may well affect the quality of family life: our food plays a more important part in daily living than merely supplying amino acids, carbohydrates, fats, vitamins and minerals. This aspect has been studied only in PKU. McBean (197I) found that out of fifty-nine families with phenylketonuric children on dietary treatment, twenty-five had serious family problems. There is other evidence of the stress caused by giving the low-phenylalanine diet (Solomons, Keleske \& Opitz, 1966; Hudson, 1971; Partington, 1971; Woolf, 1973). Several recent commercial preparations based on mixtures of pure amino acids may reduce this stress by permitting a more nearly natural diet. Further sociological and psychiatric investigation is necessary.

Dietary treatment of, e.g., galactosaemia can be life-long with only minor inconveniences after infancy. However, it has proved very difficult to keep children on a low-phenylalanine diet after they reach school age. Reports of the effects of terminating dietary treatment of PKU range from a slow intellectual deterioration over a few years (Murphy, 1963, 1969) to no detectable effect (Hudson \& Hawcroft, I973). The collaborative PKU study in the USA has started investigating the problem. Successfully treated phenylketonuric girls who, later in life, become pregnant may require re-institution of the low-phenylalanine diet during pregnancy: there is widespread damage to the foetus by high levels of phenylalanine in the maternal blood (Fisch \& Anderson, 1971; Howell \& Stevenson, 1971). Re-instituting the low-phenylalanine diet often presents psychological and other problems, but it has been accomplished in some cases (Allan \& Brown, 1968; Arthur \& Hulme, 1970).

\section{REFERENCES}

Allan, J. D. \&c Brown, J. K. (1968). In Symposium on Some Recent Advances in Inborn Errors of Metabolism, p. ${ }_{4}$ [K. S. Holt and V. P. Coffey, editors]. Edinburgh: Livingstone.

Arakawa, T. (1970). Am. F. Med. 48, 594. 
Armstrong, M. D. \& Tyler, F. H. (1955). J. clin. Invest. 34, 565 .

Arthur, L. J. H. \& Hulme, J. D. (1970). Pediatrics, Springfield 46, 235.

Auerbach, V. H. \& Di George, A. M. (1973). In Inborn Errors of Metabolism, p. 337 [F. A. Hommes and C. J. van den Berg, editors]. London and New York: Academic Press.

Baumeister, A. A. (1967). Am. F. ment. Defic. 7x, 840.

Bickel, H. (1967). In Phenylketonuria and Allied Metabolic Diseases, p. 177 [J. A. Anderson and K. F. Swaiman, editors]. Washington, DC: US Government Printing Office.

Bickel, H., Gerrard, J. \& Hickmans, E. M. (I953). Lancet ii, 812.

Bickel, H., Hudson, F. P. \& Woolf, L. I. (editors) (I971). Phenylketonuria and Some Other Inborn Errors of Amino Acid Metabolism. Stuttgart: Thieme Verlag.

Bruhl, H. H. (editor) (1966). Symposium on Nutrition and Inherited Diseases of Man as Related to Public Health. Minneapolis: Minnesota Department of Health.

Coates, S. (1961). Br. med. Y. i, 767.

Crome, L., Tymms, V. \& Woolf, L. I. (1962). Y. Neurol. Neurosurg. Psychiat. 25, 143.

Dahlqvist, A. \& Asp, N.-G. (1975). Biochem. Soc. Trans. 3, 227.

Dent, C. E. \& Westall, R. G. (1961). Archs Dis. Childh. 36, 259.

Fisch, R. O. \& Anderson, J. A. (197I). In Phenylketonuria and Some Other Inborn Errors of Amino Acid Metabolism, p. 73 [H. Bickel, F. P. Hudson and L. I. Woolf, editors]. Stuttgart: Thieme Verlag.

Fischler, K. (1971). In Phenylketonuria and Some Other Inborn Errors of Amino Acid Metabolism, p. 213 [H. Bickel, F. P. Hudson and L. I. Woolf, editors]. Stuttgart: Thieme Verlag.

Holzel, A. (1962). In Erbliche Stoffwechselkrankheiten, p. 219 [F. Linneweh, editor]. Munich: Urban and Schwarzenberg.

Howell, R. R. \& Stevenson, R. E. (1971). Social Biol. 18, Sig.

Hsia, D. Y.-Y. (editor) (1969). Galactosemia. Springfield, Illinois: C. C. Thomas.

Hudson, F. P. (1971). In Phenylketonuria and Some Other Inborn Errors of Amino Acid Metabolism, p. 273 [H. Bickel, F. P. Hudson and L. I. Woolf, editors]. Stuttgart: Thieme Verlag.

Hudson, F. P. \& Hawcroft, J. (1973). In Treatment of Inborn Errors of Metabolism, p. 51 [J. W. T. Seakins, R. A. Saunders and C. Toothill, editors]. Edinburgh and London: Churchill Livingstone.

Kalckar, H. M., Kinoshita, J. H. \& Donnell, G. N. (1973). In Biology of Brain Dysfunction, vol. 1, p. 3 I [G. E. Gaull, editor]. New York: Plenum Press.

Knox, W. E. (1972). In The Metabolic Basis of Inherited Disease, 3rd ed., p. 266 [J. B. Stanbury, J. B. Wyngaarden and D. S. Fredrickson, editors]. New York: McGraw-Hill.

Koch, R., Dobson, J. C., Blaskovics, M., Williamson, M. L., Ernest, A. E., Friedman, E. G. \& Parker, C. E. (1973). In Treatment of Inborn Errors of Metabolism, p. 3 [J. W. T. Seakins, R. $A$. Saunders and C. Toothill, editors]. Edinburgh and London: Churchill Livingstone.

Luhby, A. L., Eagle, F. J., Roth, E. \& Cooperman, J. M. (1961). Am. J. Dis. Child. 102, 482.

McBean, M. S. (1971). In Phenylketonuria and Some Other Inborn Errors of Amino Acid Metabolism, p. 280 [H. Bickel, F. P. Hudson and L. I. Woolf, editors]. Stuttgart: Thieme Verlag.

Mackenzie, D. Y. \& Woolf, L. I. (1959). Br. med. J. i, go.

Mudd, S. H., Uhlendorf, B. W., Freeman, J. M., Finkelstein, J. D. \& Shih, V. E. (1972). Biochem. biophys. Res. Commun. 46, 905

Murphy, D. (1963). Ir. Y. med. Sci. 6, 355.

Murphy, D. (1969). Ir. J. med. Sci. 8, i 77 .

Partington, M. W. (1971). In Phenylketonuria and Some Other Inborn Errors of Amino Acid Metabolism, p. 26 [H. Bickel, F. P. Hudson and L. I. Woolf, editors]. Stuttgart: Thieme Verlag.

Prader, A. \& Auricchio, S. (1965). A. Rev. Med. 16, 345.

Rosenberg, L. E. \& Mahoney, M. J. (1973). In Inborn Errors of Metabolism, p. 303 [F. A. Hommes and C. J. van den Berg, editors]. London and New York: Academic Press.

Scriver, C. R., Mackenzie, S., Clow, C. L. \& Delvin, E. (1971). Lancet i, 310.

Segal, S. (1972). In The Metabolic Basis of Inherited Disease, 3rd ed., p. 174 [J. B. Stanbury, J. B. Wyngaarden and D. S. Fredrickson, editors]. New York: McGraw-Hill.

Snyderman, S. E. (1971). In Phenylketonuria and Some Other Inborn Errors of Amino Acid Metabolism, p. 283 [H. Bickel, F. P. Hudson and L. I. Woolf, editors]. Stuttgart: Thieme Verlag.

Solomons, G., Keleske, L. \& Opitz, E. (1966). J. Pediat. 69, 596.

Walters, T. R. (1967). f. Pediat. 70, 686. 
Woolf, L. I. (1962). Adv. clin. Chem. 5, I.

Woolf, L. I. (1973). In Treatment of Inborn Errors of Metabolism, p. 57 [J. W. T. Seakins, R. A. Saunders and $C$. Toothill, editors]. Edinburgh and London: Churchill Livingstone.

Woolf, L. I., Griffiths, R. \& Moncrieff, A. A. (1955). Br. med. J. i, 57.

Woolf, L. I., Griffiths, R., Moncrieff, A. A., Coates, S. \& Dillistone, F. (1958). Archs Dis. Childh. 33, 31.

Wooff, L. I. \& Vulliamy, D. (1951). Archs Dis. Childh. 26, 487. 